\title{
Impact of COVID-19 on Food Systems and Rural Livelihoods in Ghana
}

\author{
COVID-19 Country Report - September 2020 Prepared by Louis Hodey and Fred Dzanku
}

\section{Introduction}

Given the ravaging effects of the COVID-19 pandemic worldwide, this study seeks to estimate its likely impact on food systems and livelihoods in south-western Ghana. Our sample consisted of 110 female and male respondents drawn randomly from an APRA household survey of oil palm producers in the Mpohor and Ahanta West Districts in the Western region, as well as a set of five key informant interviews. Data collection for this study will be carried out over three rounds. This report presents insights obtained from the first round conducted during June/July 2020.

\section{Context}

Ghana's first COVID-19 case was confirmed on 12 March 2020 , and the number of confirmed cases has since spiralled to 41,003 as of mid-August 2020. Initial COVID-19 mitigation measures in Ghana included a partial lockdown in Accra and Kumasi, as well as restrictions on movement and public gatherings, and the closure of schools. These restrictions are now being eased gradually.

\section{Health and disease}

Recently, there have been claims about the high level of awareness and adherence to COVID-19 protocols in Ghana. We verified these claims with our study participants. Our results show that all respondents had heard of the virus and indicated strict adherence to the safety guidelines issued by health authorities. Meanwhile, less than $2 \%$ of respondents confirmed having relatives who showed symptoms of COVID-19, while $6.4 \%$ indicated having known someone in their communities with symptoms. Just over half (55.4\%) had heard of confirmed cases in other villages in their district. Access to healthcare appeared to be quite high in our study communities.

\section{Farm labour and marketing}

We found that more than half of respondents reported reductions in their farming (55.5\%) and business (59.1\%) activities due to COVID-19. Furthermore, half of respondents (50\%) could not access off-farm work within their villages, while $64.6 \%$ could not do so outside their villages. Though access to labour and the

"We have been in so much trouble due to the coronavirus. Transport fares have gone up and we don't have money. But we have no one to help us." - Key informant, Adum-Dominase, Western Region, Ghana

"The coronavirus has brought severe livelihood challenges. Many people are poorer now as a result." - Key informant, Ahountemo, Western Region, Ghana

\section{Key findings}

- Awareness of COVID-19 and the reported level of adherence to its associated safety protocols appeared high in the study area.

- Households reported that they had reduced their movements due to the COVID-19 threat.

- Reported participation in farm and off-farm economic activities had reduced.

- Farmers reported a decline in access to output markets and their ability to acquire farm inputs due to severe financial difficulties imposed by COVID-19.

- Households reported spikes in the cost of living, as well as declining standards of living, since the start of the pandemic.

- There were emerging food insecurity concerns as a direct consequence of COVID-19.

- $\quad$ Findings point to a dip in the availability of certain food supplies, and price hikes for some food items.

- Farmers reported not receiving the desired livelihood support either from government or non-governmental organisations.

cost of hiring labour largely remained unchanged, farmers were unable to engage hired labour due to financial hardship imposed by the COVID-19 pandemic. Farmers' ability to sell their produce, particularly at the farm gate and in local markets, was reduced because of COVID-19, and transport costs have increased. This is partly explained by the sharp decline in the number of traders buying produce directly in study communities (Figure 1).

Figure 1: Changes in the number of traders visiting the community

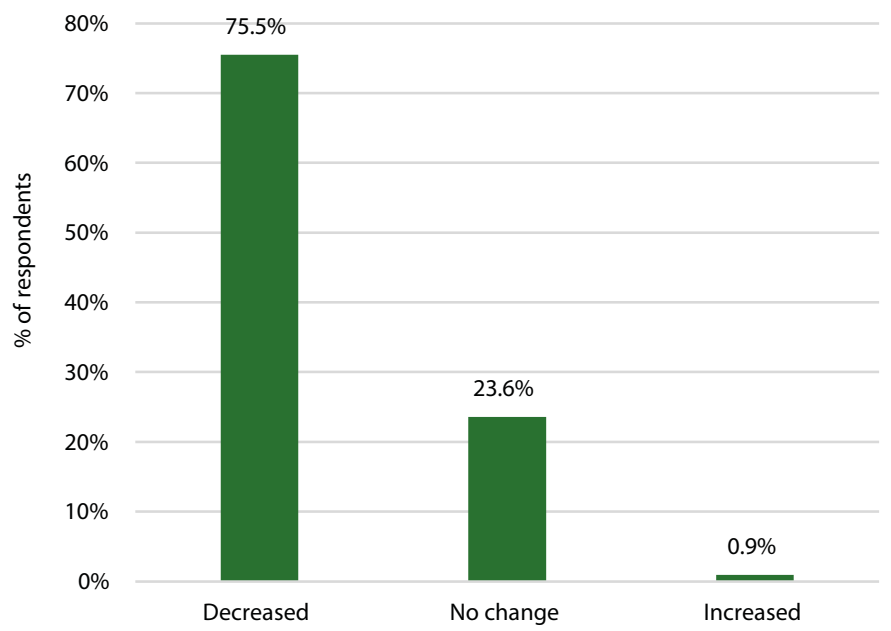




\section{Availability of services for agricultural production}

Most respondents suggested that the availability and cost of certain food production services generally remained unchanged. The majority of respondents revealed that farm production services, such as farm inputs, agriculture land for rent and agricultural extension services, were available, but their ability to access these services was constrained by financial difficulties imposed by the pandemic.

\section{Food and nutrition security}

Most respondents observed that the availability of various food items did not change as a direct result of COVID-19. However, quite a substantial proportion are of the opinion that availability of certain food items declined as a direct effect of the pandemic. Overall, $44.6 \%$ of respondents point to a decline in the availability of fish and seafood, $40.9 \%$ for white roots, tubers and plantains, and $29.1 \%$ for grains.

Similarly, quite a significant proportion of respondents observed increases in food prices as a direct effect of COVID-19, with 70.9\% reporting price hikes for fish and seafood; $65.5 \%$ for white roots, tubers and plantains; $63.6 \%$ for grains; and $58.2 \%$ for meat and poultry. Consequently, $58.2 \%$ of respondents pointed to a spike in the overall cost of living, indicating a general decline in their standard of living. Further, incidences of food insecurity were widely reported by respondents.
Figure 2: Changes to cost of living

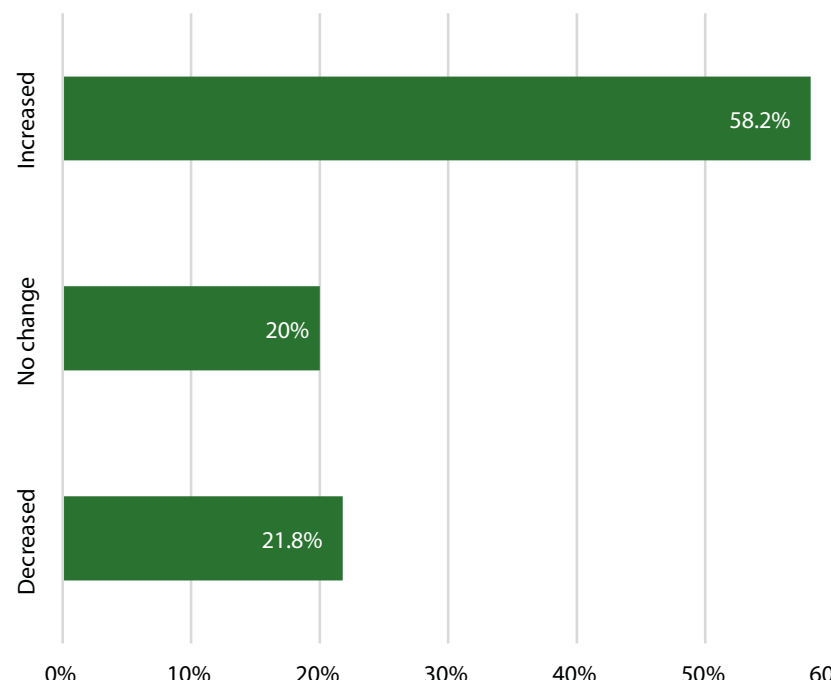

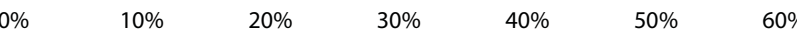

\section{Responses to the threat of COVID-19}

As a direct response to the threat of COVID-19, 71.8\% of respondents reduced their movement within their communities, and $76.4 \%$ outside their communities. Some $44.6 \%$ indicated that relatives were prevented from visiting because of the pandemic. With schools closed, children were engaged in household work, schoolwork at home, farm work, and paid work away from home. Girls appear more involved in these activities, except for paid work away from home. Generally, household care activities have increased in the study communities due to COVID-19. A key source of information and other assistance received by residents is the government $(56.4 \%)$, while $21.8 \%$ of respondents indicated having received no assistance from any source.
Figure 3: Sources of COVID-19 assistance received
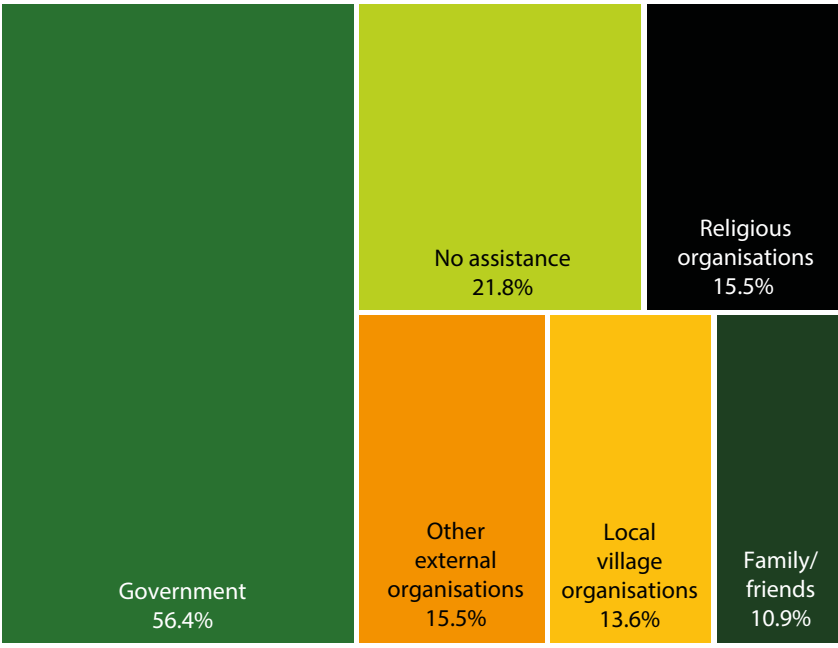
International licence (CC BY-NC-ND), which permits use and distribution in any medium, provided the original authors and source are credited, the work is not used for commercial purposes, and no modifications or adaptations are made.

If you use the work, we ask that you reference the APRA website (www.future-agricultures.org/apra/) and send a copy of the work or a link to its use online to the following address for our archive: APRA, Future Agricultures Consortium, University of Sussex, Brighton BN1 9RE, UK (apra@ids.ac.uk) 